\title{
The influence of environmental factors on male fertility and its research progress
}

\author{
Li Zhenmiao, Li Wen \\ Clinical medicine, Second Military Medical University, Shanghai, 200433, China
}

Keywords: men, fertility, environment, infertility

\begin{abstract}
Male fertility in recent years decreased rapidly, people gradually pay more attention to environmental factors, which is one of the important reasons, in order to explore and analyze the different effects of environmental factors on male fertility, of all kinds of factors, suggesting that people try to avoid damaging the environment function, pay attention to protect their fertility, prevent or slow down the process of male fertility decline. By analyzing various environmental factors leading to the decrease of male fertility, it is concluded that the reduction of male fertility is due to the combined effects of many factors, among which environmental pollution is the most important factor.

There are numerous factors that lead to male infertility, including congenital or acquired urogenital malformations, urogenital infections, endocrine disorders, genetic diseases, immunological factors, and environmental factors. But there are still $30 \%-40 \%$ of patients with unknown cause of disease [1]. The decline of human fertility is a gradual process. As people go deep into the study, they gradually give attention to the influence of environment on fertility.
\end{abstract}

\section{Effects of alcohol and tobacco on male fertility}

Effects of cigarette smoking on male fertility. There are about $37 \%{ }^{[2]}$ of the men of childbearing age smoking, smoking people in our country, the number of about 350 million, suffering from the hazards of passive smoking as high as 540 million numbers ${ }^{[3]}$. Testicular function is vulnerable to harmful substances in cigarettes, including the sperm DNA integrity and semen quality and sexual function, smoking increases ROS, resulting in oxidative stress, damage sperm function, there is evidence for a genetic and epigenetic Table ${ }^{[4]}$ shows that smoking can eventually lead to male infertility.

Influences of alcohol consumption on male fertility. Drinking will also affect male fertility, the regulating effects of neuroendocrine gonadal axis, through direct effects on testis spermatogenic and hormone produced in the environment affected by the effects on sperm quality led to a decline in the number of hormone levels decreased by ${ }^{[5]}$. Studies have shown that the incidence of ${ }^{[6]}$ male infertility is associated with heavy drinking, and alcohol consumption may be one of the principal causes of male infertility.

\section{Common physical, chemical, natural environment}

Radiations. Thermal radiation. Spermatogenesis is highly sensitive to temperature changes, and the temperature of the scrotum increases by 1-2 DEG C, which inhibits sperm production by ${ }^{\text {[7]. High }}$ temperature (> 36 C) inhibited the proliferation of Sertoli cells, integrity between Sertoli cells by high value-added and value-added cells or his contact between cells, reduce the male fertility of ${ }^{[8]}$, leading to sperm maturity is not enough, affect the survival rate of sperm.

Cold conditions also have an impact on them. A study of therapy shows that ${ }^{[9]}$ low temperatures can cause Leydig cells and Sertoli cells to undergo proliferation, and a large number of B type spermatogonia and spermatogenic cells are apoplectic.

Electromagnetic radiation. Low energy electromagnetic radiation is safe, but long-term high energy electromagnetic radiation has an effect on male fertility. After a large dose of radiation for a long time, there may be atrophy of seminiferous tubules, reduction of spermatogenic cells, disorder of the arrangement, reduction of mature sperm and disorder of epidermal secretion. Study ${ }^{[10]}$ shows 
long time exposure to mobile phone radiation rat gonadotropin decreased significantly, resulting in testicular dysfunction, increased oxidative stress, but also research shows that ${ }^{[11]} \mathrm{RF}$ radiation can significantly affect the sperm count and sperm deformity rate, but does not include sperm motility.

Ionizing radiation. Male fertility is extremely vulnerable to the effects of ionizing radiation, receiving more than $0.46 \mathrm{~Gy}$ irradiation testis will affect sperm concentration, the higher the dose, the biological effect is more serious, but this is a nonlinear dose-response relationship between the ${ }^{[12]}$ at the same time also form of ionizing radiation on sperm and sperm chromosome ${ }^{[14]}$ DNA impact $^{[13]}$.

Plateau hypoxia environments. Study 14 showed that male sperm concentration tended to decrease in the high altitude hypoxia environment. Hypoxia can result in an increase of ${ }^{[15]}$ in the level of germ cell apoptosis by oxidative stress, leading to lower levels of testosterone and related hormones, testicular tissue damage, which leads to reduced spermatogenesis and impaired testicular tissue.

Heavy metals and organic solvents. Heavy metal pollution is one of the environmental impacts of conventional chemical industry. Take the lead for example, its toxicity is mainly caused by the damage to testis, the process of hormone and spermatogenesis, and the damage to the hypothalamus and pituitary gland, thus affecting the axis of sex hormone, and indirectly affecting tests ${ }^{[16]}$. There are $^{1}$ many kinds of organic solvents, and different organic solvents affect them through diverse ways. Benzene has been demonstrated in mice testicular atrophy, oligospermia and sperm deformity, sex hormone levels decreased by ${ }^{[17]}$.

Endocrine disrupting chemicals. In industrial production, there is a class of substances known as endocrine disrupting chemicals (Endocrine, Disrupting, chemicals, EDCs). It is just an exogenous substance that interferes with the natural hormones in the organism ${ }^{[18]}$. Endocrine disrupting chemicals affect hormone dependent pathways required for gonadal development in men and women, inducing premature puberty and causing male infertility ${ }^{[19]}$.

\section{Concluding remarks}

Various environmental factors that lead to the decline of male fertility are analyzed in this paper. Male fertility decline is undoubtedly caused by many factors, including environmental pollution and a large number of chemicals penetrated into life is the most important. The effects of these factors on male fertility were not overnight, but were gradually influenced by the effects of micro doses, and when people began to pay attention, the effects were already present. Male fertility is very fragile and sensitive to the environment, and even some damage can not be repaired. All kinds of environmental pollutants and the safety of chemical raw materials need to be paid attention to. At the same time, people should understand the influence of different environments on male fertility, try to avoid harming the environment of sexual function, and pay attention to protect their fertility.

\section{References}

[1]Jungwirth A, Giwercman A, Tournaye H, Diemer T, Kopa Z, Dohle G, Krausz C; European Association of Urology Working Group on Male Infertility. European Association of Urology guidelines on Male Infertility: the 2012 update. Eur Urol., 2012, 62(2):324-32.

[2]Sharma R, Harlev A, Agarwal A, Esteves SC, Cigarette Smoking and Semen Quality: A New Meta-analysis Examining the Effect of the 2010 World Health Organization Laboratory Methods for the Examination of Human Semen. Eur Urol, 2016, 70(4):635-645.

[3]Yang Huanli, Mao Ying. Research progress of smoking on reproductive hazards. Chinese health education, 2011, 27 (9): 705-707.

[4]Harlev A, Agarwal A, Gunes SO, Shetty A, du Plessis SS. Smoking and Male Infertility: An Evidence-Based Review. World J Mens Health, 2015, 33(3):143-60. 
[5]Akomolafe SF, Oboh G, Akindahunsi AA, Afolayan AJ. Ethanol-induced male infertility: Effects of aqueous leaf extract of Tetracarpidium conophorum.. Andrologia, 2017, doi: 10.1111/and.12759.

[6] He Jiang, Yu Wuzhong, Liu Hongchun, Zou Hongyun. Influence of drinking on the quality of male semen. Chinese Journal of eugenics and genetics, 2008, 16 (10): 103-105.

[7] Liu Anna, Wang Y H. Analysis of the influence of high temperature working environment on semen quality in male. Chinese Journal of eugenics and genetics, 2015, 23 (2): 116-124.

[8]Hu JT, Shao CH, Wang PT, Liu Y, Hao WY, Feng YL, Liu SH, Wang XS. High temperature reduces the proliferation of and occludin expression in rat Sertoli cells in vitro. Zhonghua Nan Ke Xue. 2012, 18(10):920-4.

[9]de Alvarenga ER, de França LR. Effects of different temperatures on testis structure and function, with emphasis on somatic cells, in sexually mature Nile tilapias (Oreochromis niloticus). Biol Reprod, 2009, 80(3):537-44.

[10]Oyewopo AO1, Olaniyi SK2, Oyewopo CI3, Jimoh AT. Radiofrequency electromagnetic radiation from cell phone causes defective testicular function in male Wistar rats. Andrologia, 2017. doi: 10.1111/and.12772. (Epub ahead of print)

[11]Yildirim ME1, Kaynar M2, Badem H3, Cavis M4, Karatas OF4, Cimentepe E. What is harmful for male fertility: cell phone or the wireless Internet? Kaohsiung J Med Sci, 2015, 31(9):480-4.

[12]Little MP. Risks associated with ionizing radiation. British Medical Bulletin, 2003, 68: 259-275.

[13]Barratt CL, Aitken RJ, Bj ö rndahl L, et al. Sperm DNA: organization, protection and vulnerability: from basic science to clinical applications - a position report. Hum Reprod, 2010,25: 824-838.

[14]Wan Lin. Progress in the study of the effects of high altitude hypoxia on sperm concentration in men. Chinese Journal of andrology, 2012,18 (9): 835 - 839.

[15]Zepeda AB1, Figueroa CA1, Calaf GM2,3, Farías JG. Male reproductive system and antioxidants in oxidative stress induced by hypobaric hypoxia. Andrologia, 2014, 46(1):1-8.

[16] Li Yumin, Han Yunxian, Luo Zhibin. Male infertility and living environment. Chinese and foreign medical research, 2011,9 (32): 152-156.

[17]Luderer U1, Bushley A, Stover BD, Bremner WJ, Faustman EM, Takaro TK, Checkoway H, Brodkin CA. Effects of occupational solvent exposure on reproductive hormone concentrations and fecundability in men. Am J Ind Med, 2004, 46(6):614-26.

[18]Kavlock J R. Research needs for the risk assessment of health and environmental effects of endocrine disruptor: areport of the US sponsored. Environ Health Perspect, 1996, 104(4):715-740.

[19]Sifakis S, Androutsopoulos VP, Tsatsakis AM, Spandidos DA. Human exposure to endocrine disrupting chemicals: effects on the male and female reproductive systems. Environ Toxicol Pharmacol. 2017, 51:56-70. 